\title{
The possible link between insulin resistance and increased cardiovascular mortality
}

Address: ${ }^{1}$ Department of Pharmacology and Pharmacotherapy, University of Debrecen, Hungary, ${ }^{2}$ Department of Anesthesiology and ICU, Petz Aladár County Hospital, Győr, Hungary and ${ }^{3}$ Department of Biochemistry and Molecular Biology, University of Debrecen, Hungary

Email: Barna Peitl* - barna.peitl@king.pharmacol.dote.hu

* Corresponding author

from I3th Scientific Symposium of the Austrian Pharmacological Society (APHAR). Joint Meeting with the Austrian Society of Toxicology (ASTOX) and the Hungarian Society for Experimental and Clinical Pharmacology (MFT)

Vienna, Austria. 22-24 November 2007

Published: 14 November 2007

BMC Pharmacology 2007, 7(Suppl 2):A48 doi:10.1 I86/I47|-2210-7-S2-A48

This abstract is available from: http://www.biomedcentral.com/I47I-22/0/7/S2/A48

C 2007 Peitl et al; licensee BioMed Central Ltd.

\section{Introduction}

Hyperinsulinaemia and insulin resistance are considered as independent risk factors of ischemic heart disease. We sought whether hyperinsulinaemia per se is of significant influence on cardiac arrhythmia generation in conscious rabbits.

\section{Methods}

Chronically instrumented conscious rabbits were equipped with a right ventricular electrode catheter for pacing and recording the intracavitary electrogram as well as with arterial and venous catheters for blood sampling, blood pressure monitoring and for insulin and glucose infusions, respectively. Hyperinsulinaemia was produced by 2-step hyperinsulinaemic ( $35.7 \pm 7.4$ and $103.2 \pm 10.5$ $\mu \mathrm{U} / \mathrm{ml})$ euglycaemic $(5.5 \pm 0.5 \mu \mathrm{U} / \mathrm{ml})$ glucose clamping. Programmed electrical stimulation (PES) was applied for ventricular effective refractory period (VERP) determination and arrhythmia generation.

\section{Results}

The VERP shortened from $110.4 \pm 3.7$ to $104.8 \pm 2.9 \mathrm{~ms}$, $(\mathrm{p}<0.05)$ and from $109.3 \pm 2.9$ to $101.4 \pm 1.7 \mathrm{~ms}(\mathrm{p}<$ 0.05 ) in animals with 35 and $103 \mu \mathrm{U} / \mathrm{ml}$ clamped hyperinsulinaemic euglycaemia, respectively. The incidence of ventricular premature beats, non-sustained ventricular tachycardia and sustained ventricular tachycardia induced by PES increased from control $11,0,0 \%$ to 24 ( $\mathrm{p}<0.05)$, 5, $0 \%$; and 56, 44 ( $<<0.001$ for each), $0 \%$ in animals with 35 and $103 \mu \mathrm{U} / \mathrm{ml}$ clamped hyperinsulinaemic euglycaemia, respectively.

\section{Conclusion}

The results provide evidence for the "sui generis" proarrhythmic effect of hyperinsulinaemia in otherwise healthy rabbits. The results also suggest that this is underpinned by a hyperinsulinaemia-induced reduction of VERP. 